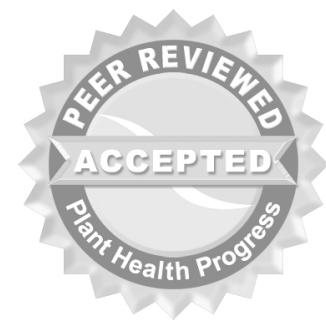

(C) 2011 Plant Management Network.

Accepted for publication 2 March 2011. Published 25 April 2011.

\title{
Root Rot of Dry Edible Bean Caused by Fusarium graminearum
}

\author{
V. N. Bilgi, Department of Plant Pathology, North Dakota State \\ University, Fargo, ND 58108; C. A. Bradley, Department of Crop \\ Sciences, University of Illinois, Urbana, IL 61801; F. M. Mathew, \\ S. Ali, and J. B. Rasmussen, Department of Plant Pathology, North \\ Dakota State University, Fargo, ND 58108
}

Corresponding author: C. A. Bradley. carlbrad@illinois.edu

Bilgi, V. N., Bradley, C. A., Mathew, F. M., Ali, S., and Rasmussen, J. B. 2011. Root rot of dry edible bean caused by Fusarium graminearum. Online. Plant Health Progress doi:10.1094/PHP-2011-0425-01-RS.

\begin{abstract}
Fusarium graminearum was identified as a root pathogen of a diverse array of dry edible bean genotypes under both field and greenhouse conditions in North Dakota. In comparisons under controlled conditions, root rot caused by $\mathrm{F}$. graminearum was equal or greater than that caused by F. solani f. sp. phaseoli. Out of eleven dry bean genotypes evaluated in controlled conditions, Eclipse, VAX 3, and T-39 had the lowest root rot severity values for both F. graminearum and F. solani f. sp. phaseoli. A significant and positive correlation between genotype response to $\mathrm{F}$. graminearum and $\mathrm{F}$. solani f. sp. phaseoli indicates that genetic resistance to both pathogens may be related.
\end{abstract}

\section{I ntroduction}

Fusarium root rot is one of the major yield-limiting diseases of dry edible bean (Phaseolus vulgaris L.) in North Dakota and Minnesota production regions (13). More dry edible beans are produced in North Dakota and Minnesota than in any other region in the United States. Dry edible bean market classes grown in North Dakota and Minnesota include black, great northern, red kidney, navy, pinto, and a few other specialty classes. Previously, most Fusarium root rot of dry edible bean was considered to be caused by Fusarium solani (Mart.) Sacc. f. sp. phaseoli W.C. Snyder \& H.N. Hansen (Fsp) (6). Recently, several reports of F. graminearum Schwabe (Fg) causing disease on below-ground tissues of dicotyledonous plants have been published $(1,4,5,7,8,12,17)$. In North Dakota and Minnesota, $\mathrm{Fg}$ is very common and causes Fusarium head blight on barley (Hordeum vulgare L.) and wheat (Triticum aestivum L.) (16). The objectives of our research were to: (i) determine if a pathogenic association between Fg and dry edible bean occurs under natural field conditions; (ii) test Fg isolates from dry edible bean to compare aggressiveness with an Fsp isolate; and (iii) evaluate dry edible bean genotypes for resistance to root rot caused by Fg and Fsp.

\section{Dry Edible Bean Genotype Field Study}

General methods. Dry edible bean genotypes Eclipse (black bean), Maverick (pinto bean), Norstar (navy bean), Red Hawk (dark red kidney bean), and Rojo Chiquito (small red bean) were planted into a field in Fargo, ND, at the North Dakota State University Agricultural Experiment Station on 1 June 2006 into a Fargo clay soil (fine, smectitic, frigid Typic Epiaquerts). Planting depth was approximately $4 \mathrm{~cm}$. Each plot was 4 rows wide (38 cm centers) and $4.6 \mathrm{~m}$ long. The field had been planted to spring wheat and used for Fusarium head blight fungicide research trials in 2005. The experimental design was a randomized complete block (RCB) with 4 replications. The field study originally was designed to be a dry bean cultivar yield and performance test, but served as a source of Fusarium isolates for further studies and as a preliminary trial in which dry bean genotypes could be compared for root rot severity. 
Fusarium graminearum from roots. Fusarium pathogens causing root rot were identified through isolations as follows. On 29 June, twenty plants per plot were arbitrarily chosen and dug, collected, and taken to the laboratory. Roots were removed from the plants, washed to remove soil, and cut into sections approximately $1 \mathrm{~cm}$ in length. Root pieces from all plants were combined, and 50 root pieces were selected arbitrarily, surface sterilized in a $0.5 \%$ solution of $\mathrm{NaOCl}$ for $2 \mathrm{~min}$, rinsed in sterile distilled water three times, and placed into petri dishes containing Komada's medium (14).

All Fusarium isolates that grew from the plated roots appeared to be Fg according to morphological characters (15). To confirm the identification, six isolates were sent to the Fusarium Research Center (Penn State University, University Park, PA). All six isolates were confirmed as Fg through morphological characters by the Fusarium Research Center, and for five of the isolates, partial translation elongation factor 1-alpha sequences were generated for identification as described by Geiser et al. (11). The sequences from the five isolates were $99 \%$ to $100 \%$ identical to $\mathrm{Fg}$. The mean number of plated root pieces (out of 50) in which Fg was isolated from each genotype is shown in Table 1 . These data were analyzed using the general linear models procedure (PROC GLM) of SAS (Version 9.2, SAS Institute Inc., Cary, NC), and means were compared using Fisher's protected least signficant difference (LSD), where $\alpha=0.05$. Genotypes did not significantly differ for the number of roots in which Fg was recovered.

Table 1. Root rot severity and number of roots in which Fusarium graminearum was isolated from different dry bean genotypes growing in a field located in Fargo, ND.

\begin{tabular}{|l|c|c||}
\hline Genotype & $\begin{array}{c}\text { Root rot severity } \\
(1 \text { to } 7)^{x}\end{array}$ & $\begin{array}{c}\text { Root pieces with } \\
\text { F. graminearum (no. })^{x y}\end{array}$ \\
\hline Red Hawk & $4.3 \mathrm{a}$ & $6.3 \mathrm{a}$ \\
\hline Rojo Chiquito & $4.3 \mathrm{a}$ & $3.0 \mathrm{a}$ \\
\hline Maverick & $3.5 \mathrm{~b}$ & $6.8 \mathrm{a}$ \\
\hline Norstar & $2.4 \mathrm{c}$ & $2.3 \mathrm{a}$ \\
\hline Eclipse & $2.0 \mathrm{c}$ & $2.0 \mathrm{a}$ \\
\hline
\end{tabular}

$\mathrm{x}$ Means within a column followed by the same letter are not significantly different according to Fisher's protected least significant difference $(a=0.05)$.

$y$ Represents the mean number of root pieces that yielded $F$. graminearum colonies. A total of 50 root pieces collected from each plot were plated onto Komada's medium.

Root rot severities. Dry edible bean genotypes were assessed for root rot severity in the field. On 12 August, ten plants from each plot were dug, roots were washed to remove soil, and roots were rated for root rot severity using a 1 to 7 scale described by Schneider and Kelly (18), where: 1 = healthy roots with no discoloration of root or hypocotyl and no reduction in root mass; $2=0.1$ to $0.2 \mathrm{~cm}$ small reddish brown lesions at the base of the hypocotyl, with normal root mass and size; 3 = increase in intensity and size and coalescing of localized root/hypocotyl lesions approximately $180^{\circ}$ around the stem, with lesions from 0.5 to $1 \mathrm{~cm}$ and 10 to $20 \%$ root discoloration but no reduction in root mass size; 4 = increase in intensity of discoloration and size of hypocotyl lesions, with lesions extending and completely encircling the stem, 5 to $10 \%$ root mass reduction, and $95 \%$ of the roots discolored; $5=$ increasingly discolored and extended hypocotyl lesions, with $100 \%$ of the roots intensely reddish-brown and 20 to $50 \%$ root mass reduction; 6 = hypocotyl lesions encircling the stem extending up to $2 \mathrm{~cm}$, intense root mass discoloration, and 50 to $80 \%$ root mass reduction; and $7=$ pithy or hollow hypocotyl with very extended lesions, 80 to $100 \%$ root mass reduction, and functionally dead. Data were analyzed using PROC GLM in SAS, and means were compared using Fisher's protected LSD, where $\alpha=0.05$. 
The dry edible bean genotypes in the field differed significantly for root rot severity. The genotype Eclipse had the lowest root rot severity rating, which was significantly lower than the root rot ratings for all other genotypes except Norstar (Table 1). The genotypes Red Hawk and Rojo Chiquito had the same root rot rating, which was significantly greater than the ratings for all other genotypes.

\section{Pathogenicity and Aggressiveness of Fusarium graminearum I solates}

General methods. Three Fg isolates (denoted as R-10062, R-10063, and R10064) collected from the dry edible bean genotype field study in Fargo, ND, and one Fsp isolate originally collected from a dry bean field near Staples, MN, were used to inoculate the roots of the dry bean genotype Montcalm (dark red kidney bean) to determine their pathogenicity and aggressiveness. A potted plant assay with a modified inoculum layer technique (3) was used in the greenhouse. Inoculum was prepared by growing each isolate on autoclaved sand-cornmeal for 1 week at 22 to $25^{\circ} \mathrm{C}$ under a 12-h light/dark cycle. Two pregerminated seeds of 'Montcalm' were planted in 9-cm plastic pots containing steam-pasteurized potting mix (Sunshine Mix no. 1; Sun Gro Horticulture Ltd., Seba Beach, AB, Canada). The seeds were covered with a thin layer of potting mix, followed by $10 \mathrm{~g}$ of Fsg or Fsp sand-cornmeal inoculum and more potting mix (approximately $5 \mathrm{~g}$ ). As negative controls, a non-infested sand-cornmeal mixture and a no sand-cornmeal mixture treatments also were included. Pots were watered to saturation after planting in the greenhouse and lightly watered on alternate days. The greenhouse temperature ranged from 20 to $22^{\circ} \mathrm{C}$. Natural sunlight was supplemented with fluorescent lights that were set for a 12-h light/dark cycle. Each individual pot represented an experimental unit, and each experiment consisted of five replications per treatment. Eighteen days after planting, plants were removed from the soil and the roots were washed. Root rot severity was evaluated using a 1 to 7 scale (18). Pieces of symptomatic and healthy root tissue (negative controls) were surface sterilized in a $0.5 \%$ solution of $\mathrm{NaOCl}$ for $2 \mathrm{~min}$, rinsed in sterile distilled water three times, and placed into petri dishes containing potato dextrose agar (PDA; Becton Dickinson and Company, Sparks, MD) to recover Fusarium species, and the identities of Fusarium species were confirmed by morphology characteristics (15). The experiment was repeated. The statistical design was a RCB. Data were analyzed using PROC GLM in SAS. No significant $(\mathrm{P} \leq 0.05)$ experiment $\times$ isolate interaction was observed, therefore, the data from the two experiments were combined for analysis. Means were compared using Fisher's protected LSD, where $\alpha=0.05$.

Pathogenicity and aggressiveness of isolates. All Fg isolates and the Fsp isolate caused significantly greater root rot severity on the dry bean genotype Montcalm compared to the negative control treatments (Table 2). Both Fg and Fsp cultures were recovered from roots that were inoculated with the respective isolates, no Fusarium cultures were recovered from negative control treatments. Fg isolates differed in the level of root rot severity they caused, but the range of root rot severity values was not wide (range of 2.5 to 3.0). Roots inoculated with the Fg isolates had significantly greater root rot severity than those inoculated with the Fsp isolate. Root rot symptoms caused by Fg and Fsp were similar (Fig. 1). 
Table 2. Comparison of three Fusarium graminearum $(\mathrm{Fg})$ isolates and a F. solani f. sp. phaseoli (Fsp) isolate for their aggressiveness in causing root rot severity on 'Montcalm' dry bean using an inoculum layer inoculation technique in the greenhousex.

\begin{tabular}{|l|c|}
\hline I solatezx & Root rot severity (1-7)y \\
\hline Fsp & $1.7 \mathrm{c}$ \\
\hline Fg R-10062 & $2.5 \mathrm{~b}$ \\
\hline Fg R-10063 & $2.8 \mathrm{ab}$ \\
\hline Fg R-10064 & $3.0 \mathrm{a}$ \\
\hline Non-infested sand-cornmeal control & $1.0 \mathrm{~d}$ \\
\hline No sand-cornmeal control & $1.0 \mathrm{~d}$ \\
\hline
\end{tabular}

$x$ Results reported were averaged over two trials.

$y$ Values followed by the same letter are not significantly different according to Fisher's protected least significant difference $(a=0.05)$.
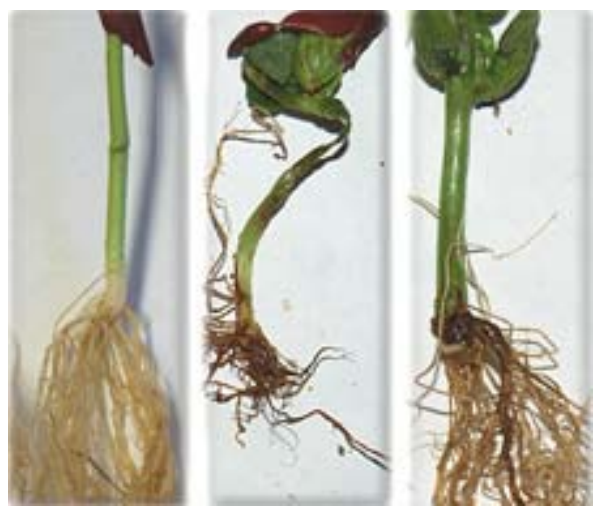

Fig. 1. Comparison of root rot symptoms caused by Fusarium graminearum and $\mathrm{F}$. solani f. sp. phaseoli on 'Montcalm' dry bean: ( $L$ to $R$ ) healthy roots, root rot caused by $F$. graminearum, and root rot caused by $\mathrm{F}$. solani f. sp. phaseoli.

\section{Evaluation of Dry Bean Genotypes for Resistance to Fusarium} graminearum and Fusarium solani f. sp. phaseoli

General methods. The dry bean genotypes Eclipse (black bean), Matterhorn (great northern bean), Maverick (pinto bean), Montcalm (dark red kidney bean), Norstar (navy bean), Othello (pinto bean), Red Hawk (dark red kidney bean), Rojo Chiquito (small red bean), T-39 (black bean), VAX 3 (small red bean), and Vista (navy bean) were evaluated for their resistance to Fg and Fsp using a "paper towel inoculation method" described by Bilgi et al. (3). This method had been used previously to screen dry bean genotypes for resistance to Fsp (3). To determine if this method would work with Fg, a preliminary trial was conducted with 'Montcalm.' The results of the preliminary trial indicated that Fg caused significantly greater root rot severity on Montcalm compared to the negative control treatments using this method (Mathew, Bradley, and Rasmussen, unpublished). The paper towel inoculation methods used to evaluate dry bean genotypes for resistance to Fg, briefly described, were: seeds were planted into $266-\mathrm{cm}^{3}$ drinking cups filled with vermiculite and placed into a growth chamber maintained at $14 \mathrm{~h}$ of light and $10 \mathrm{~h}$ of darkness with day and night temperatures of 21 and $18^{\circ} \mathrm{C}$, respectively. After plants grew in the vermiculite for 10 days, they were removed from the cups, washed, and placed onto layers of bleached paper towels. Roots within the paper towels were inoculated with sterilized wheat grains infested with either an Fg isolate originally collected from a wheat field in Ransom County, ND (designated as isolate R4), or an Fsp isolate originally collected from a dry bean field near Staples, MN. After inoculating, plants were wrapped inside paper towels, 
moistened with sterilized distilled water, and placed in a plastic bag inside the growth chamber. Plastic bags were placed in an aluminum stand that allowed the plants to be upright. Plants were removed 10 days after inoculation and the roots were rated using a 1 to 7 root rot severity scale (18). Two roots were inside each plastic bag, and each plastic bag was considered an experimental unit. The experimental design was a RCB with 4 replications, and the experiment was repeated. Data were analyzed using PROC GLM in SAS. No significant $(\mathrm{P} \leq 0.05)$ experiment $\times$ treatment interaction was observed, therefore, the data from the two experiments were combined for analysis. Least-square means (LSMEANS) were calculated and t-test comparisons among dry bean genotypes and between Fusarium isolates were made using the PDIFF option in SAS. Spearman's rank correlation (PROC CORR SPEARMAN) was used in SAS to determine the relationship between genotype responses to Fg and Fsp.

Reaction of dry bean genotypes. A significant $(\mathrm{P}<0.0001)$ dry bean genotype $\times$ Fusarium isolate interaction was detected; therefore, data are presented by Fusarium isolate (Table 3). The dry bean genotype Rojo Chiquito had the greatest root rot severity caused by Fg compared to all other genotypes. The dry bean genotype T-39 had the least root rot severity caused by Fg compared to all other genotypes, but was not significantly different than VAX 3. Similar to the Fg root rot reaction, genotype Rojo Chiquito had the greatest root rot severity caused by Fsp compared to all other genotypes, but was not significantly different than Montcalm. The genotypes Eclipse, VAX 3, and T-39 had the least root rot severity caused by Fsp compared to all other genotypes. For all genotypes except Matterhorn and Othello, the Fg isolate caused significantly $(\mathrm{P} \leq \mathrm{0.05})$ more severe root rot compared to the Fsp isolate. Spearman's rank correlation analysis indicated that a positive (Spearman's rank correlation coefficient $=0.89)$ and significant $(\mathrm{P}<0.0001)$ correlation was present between genotype response to Fg and Fsp.

Table 3. Root rot severity reactions of dry edible bean genotypes inoculated with Fusarium graminearum or F. solani f. sp. phaseoli using a paper towel method in a growth chamberx.

\begin{tabular}{|l|c|c|c|}
\hline Genotype & Fgy & Fspy & P > F z \\
\hline Rojo Chiquito & $6.2 \mathrm{a}$ & $5.0 \mathrm{a}$ & 0.0001 \\
\hline Red Hawk & $5.4 \mathrm{~b}$ & $4.5 \mathrm{bc}$ & 0.0001 \\
\hline Montcalm & $5.3 \mathrm{~b}$ & $4.9 \mathrm{ab}$ & 0.0153 \\
\hline Maverick & $5.1 \mathrm{bc}$ & $4.2 \mathrm{~cd}$ & 0.0001 \\
\hline Matterhorn & $4.6 \mathrm{~cd}$ & $4.3 \mathrm{~cd}$ & 0.0510 \\
\hline Othello & $4.5 \mathrm{~d}$ & $4.1 \mathrm{~d}$ & 0.0510 \\
\hline Vista & $4.3 \mathrm{de}$ & $3.2 \mathrm{e}$ & 0.0001 \\
\hline Norstar & $4.0 \mathrm{e}$ & $3.5 \mathrm{e}$ & 0.0008 \\
\hline Eclipse & $3.5 \mathrm{f}$ & $1.9 \mathrm{f}$ & 0.0001 \\
\hline VAX 3 & $3.2 \mathrm{fg}$ & $1.9 \mathrm{f}$ & 0.0001 \\
\hline T-39 & $3.1 \mathrm{~g}$ & $2.1 \mathrm{f}$ & 0.0001 \\
\hline Mean & 4.5 & 3.6 & 0.0001 \\
\hline
\end{tabular}

${ }^{x}$ Results reported were averaged over two trials.

Y Root rot severity (1 to 7) caused by Fusarium graminearum (Fg) or F. solani f. sp. phaseoli (Fsp). Values followed by the same letter within a column are not significantly different according to least-square mean t-tests $(a=0.05)$.

$\mathrm{z}$ P-value for the comparison between Fg and Fsp within a row. 


\section{Discussion}

From our research results, we report here the first confirmation of a pathogenic association between Fg and dry edible bean based on field infection. Chongo et al. (8) reported that when inoculated under controlled conditions with an Fg isolate collected from a wheat head, dry bean had severe root rot and reduced seedling emergence. Under field infection conditions in our study, Fg caused root rot on five different dry bean genotypes, each representing a different market class. As a root rotting pathogen, Fg was equal or had significantly greater aggressiveness on dry bean roots compared to Fsp under controlled conditions in our research. In comparisons of Fg and Fsp in our research trials, only one Fsp isolate was used. Comparisons of additional Fsg and Fsp isolates from diverse locations are needed to verify if Fg generally causes greater root rot severity on dry bean compared to Fsp.

Dry bean genotypes differed in their response to $\mathrm{Fg}$ based primarily on differences in disease severity. This indicates that a type of partial resistance to Fg root rot may be present in some genotypes. Three genotypes (Eclipse, VAX 3, and T-39) had Fg root rot severity values lower than all other genotypes tested. All three of these genotypes represent market classes that have been developed from the Mesoamerican gene pool. This is interesting in that genotypes developed from the small-seeded Mesoamerican gene pool generally have been less susceptible to Fsp root rot compared to genotypes developed from the large-seeded Andean gene pool (2). In addition, these same three genotypes (Eclipse, VAX 3, and T-39) had the lowest Fsp root rot severity values compared to other genotypes. Bilgi et al. (3) had the same finding in both field and controlled conditions. Considering that the same three genotypes had the lowest root rot severity ratings for both Fusarium species and that a strong and significant correlation existed between genotype reactions to Fg and Fsp, it is likely that genotypes that have resistance to Fg will have resistance to Fsp, and vice versa. Additional research is needed to better understand this relationship and the number of genes involved in root rot resistance.

In light of our findings, growers that plant dry edible bean following wheat or barley fields that were affected by Fusarium head blight may need to consider root rot management tactics such as planting a cultivar with a high level of Fusarium root rot resistance or applying a fungicide seed treatment. Ellis et al. (10) reported that fungicide seed treatments could reduce disease on soybean seedlings caused by Fg. Our findings may have implications beyond dry bean production. Rotation with nongramineous crops has been a management practice used to help control Fusarium head blight (caused by Fg) of wheat and barley $(9,19)$. More research is needed to understand how the pathogenic relationship between Fg and dry bean will affect Fg diseases in other crops. In addition, the prevalence of Fg root rot on dry bean is not known, and focused surveys are needed to determine this.

\section{Acknowledgements}

We thank the Northarvest Bean Growers Association and the North Dakota State Board of Agricultural Research and Education for funding this research. Additionally, we thank D. Geiser at the Fusarium Research Center at Penn State University for identifying Fusarium isolates and S. Khot and C. Chesrown for assistance with the research trials.

\section{Literature Cited}

1. Ali, S., Rivera, V. V., and Secor, G. A. 2005. First report of Fusarium graminearum causing dry rot of potato in North Dakota. Plant Dis. 89:105.

2. Beebe, S. E., Bliss, F. A., and Schwartz, H. F. 1981. Root rot resistance in common bean germ plasm of Latin American origin. Plant Dis. 65:485-489.

3. Bilgi, V. N., Bradley, C. A., Khot, S. D., Grafton, K. F., and Rasmussen, J. B. 2008. Response of dry bean genotypes to Fusarium root rot, caused by Fusarium solani f. sp. phaseoli, under field and controlled conditions. Plant Dis. 92:1197-1200.

4. Bradley, C. A. 2008. Effect of fungicide seed treatments on stand establishment, seedling disease, and yield of soybean in North Dakota. Plant Dis. 92:120-125. 
5. Broders, K. D., Lipps, P. E., Paul, P. A., and Dorrance, A. E. 2007. Evaluation of Fusarium graminearum associated with corn and soybean seed and seedling disease in Ohio. Plant Dis. 91:1155-1160.

6. Burke, D. W., Hall, R., Harveson, R. M., and Yuen, G. 2005. Fusarium root rot. Pages 13-15 in: Compendium of Bean Diseases, 2nd Edn. H. F. Schwartz, J. R. Steadman, R. Hall, and R. L. Forster, eds. American Phytopathological Society, St. Paul, MN.

7. Burlakoti, R. R., Estrada, R., Jr., Rivera, V. V., Boddeda, A., Secor, G. A., and Adhikari, T. B. 2007. Real-time PCR quantification and mycotoxin production of Fusarium graminearum in wheat inoculated with isolates collected from potato, sugar beet, and wheat. Phytopathology 97:835-841.

8. Chongo, G., Gossen, B. D., Kutcher, H. R., Gilbert, J., Turkington, T. K., Fernandez, M. R., and McLaren, D. 2001. Reaction of seedling roots of 14 crop species to Fusarium graminearum from wheat heads. Can. J. Plant Pathol. 23:132-137.

9. Dill-Macky, R. 1997. Head blight (scab). Pages 51-53 in: Compendium of Barley Diseases, 2nd Edn. D. E. Mathre, ed. American Phytopathological Society, St. Paul, MN.

10. Ellis, M. L., Broders, K. D., Paul, P. A., and Dorrance, A. E. 2011. Infection of soybean seed by Fusarium graminearum and effect of seed treatments on disease under controlled conditions. Plant Dis. 95:401-407.

11. Geiser, D. M., del Mar Jimenez-Gasco, M., Kang, S., Makalowska, I., Veeraraghavan, N., Ward, T. J., Zhang, N., Kuldau, G. A., and O’Donnell, K. 2004. FUSARIUM-ID v. 1.0: A DNA sequence database for identifying Fusarium. Eur. J. Plant Pathol. 110:473-479.

12. Hanson, L. E. 2006. Fusarium yellowing of sugar beet caused by Fusarium graminearum from Minnesota and Wyoming. Plant Dis. 90:686.

13. Knodel, J. J., Bradley, C. A., Luecke, J. L., and Mars, G. A. 2007. 2004 and 2005 dry bean grower survey. Coop. Ext. Rep. No. PP-1265. North Dakota State Univ., Fargo, ND.

14. Komada, H. 1975. Development of a selective medium for quantitative isolation of Fusarium oxysporum from natural soil. Rev. Plant Prot. Res. 8:114-125.

15. Leslie, J. F., and Summerell, B. A. 2006. The Fusarium Laboratory Manual. Blackwell Publ. Professional, Ames, IA.

16. McMullen, M., Jones, R., and Gallenberg, D. 1997. Scab of wheat and barley: a reemerging disease of devastating impact. Plant Dis. 81:1340-1348.

17. Pioli, R. N., Mozzoni, L., and Morandi, E. N. 2004. First report of pathogenic association between Fusarium graminearum and soybean. Plant Dis. 88:220.

18. Schneider, K. A. and Kelly, J. D. 2000. A greenhouse screening protocol for Fusarium root rot in bean. HortScience 35:1095-1098.

19. Wiese, M. V. 1987. Compendium of Wheat Diseases, 2nd Edn. American Phytopathological Society, St. Paul, MN. 